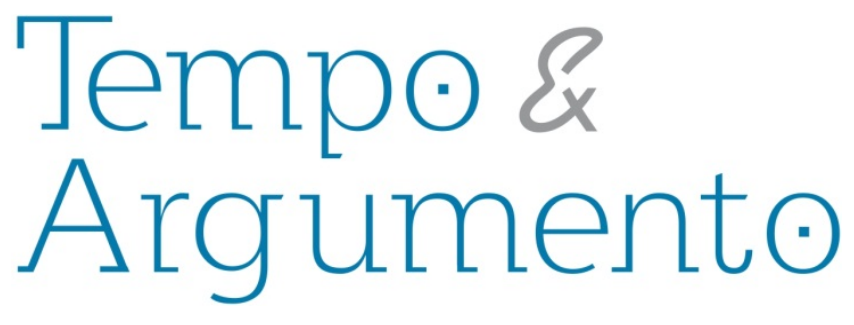

\title{
Intolerância ao Sul da América: estudo comparado de grupos fascistas do Brasil e da Argentina na Internet (1996-2007)
}

\begin{abstract}
Resumo
Este artigo investiga os usos da internet realizados por grupos de fascistas do Brasil e da Argentina. Utilizamos como principais fontes sites declaradamente fascistas criados pouco depois da popularização da internet. Através da perspectiva oferecida pela metodologia comparativa defendida por Marc Bloch, o texto analisa a relação entre as homepages brasileiras e o mais conhecido site sul-americano de extrema direita, Ciudad Libertad Opinión, criado em 1999, com a principal finalidade de disseminar ideias fascistas e prestar apoio a outros grupos extremistas. Apontamos o papel estratégico que o portal Libre Opinión cumpriu como articulador entre os grupos fascistas da América do Sul, sendo um colaborador fundamental na difusão de páginas brasileiras marcadas por veicularem regularmente mensagens xenófobas, racistas, antissemitas e homofóbicas.
\end{abstract}

\author{
Dilton Cândido Santos Maynard \\ Doutor em História pela Universidade \\ Federal de Pernambuco (UFPE). Professor \\ do Departamento de História da \\ Universidade Federal de Sergipe (UFS). \\ Brasil \\ dilton@getempo.org
}

Palavras-chave: Fascismo - Brasil; Fascismo - Argentina;

Internet; América do sul.

\section{Para citar este artigo:}

MAYNARD, Dilton Cândido Santos. Intolerância ao Sul da América: estudo comparado de grupos fascistas do Brasil e da Argentina na Internet (1996-2007). Revista Tempo e Argumento, Florianópolis, v. 6, n.12, p. 54 - 84, mai./ago. 2014.

DOI: $10.5965 / 2175180306122014054$

http://dx.doi.org/10.5965/2175180306122014054 


\title{
Intolerance South of America: Comparative study of fascist groups from Brazil and Argentina on the Internet (1996-2007)
}

\begin{abstract}
This article investigates the uses of the Internet made by fascist groups from Brazil and Argentina. We use as main sources professedly fascist websites created shortly after the popularization of the Internet. From the perspective offered by the comparative methodology advocated by Marc Bloch, the text examines the relation between Brazilian homepages and the best known South American far-right website, Ciudad Libertad Opinión, created in 1999 with the primary purpose of spreading fascist ideas and providing support to other extremist groups. We point out the strategic role played by the web portal Libre Opinión as articulator between fascist groups in South America, this is a key contributor in the diffusion of Brazilian web pages marked to convey on a regular basis xenophobic, racist, anti-Semitic, and homophobic messages.
\end{abstract}

Keywords: Fascism - Brazil; Fascism - Argentina; Internet; South America

\section{A rede, os jovens, o mundo}

“- Começo pelos jovens [...] Nós, mais velhos, estamos desgastados. [...] Mas meus maravilhosos jovens! Será que existem melhores no mundo?", observou certa vez Adolf Hitler (1889-1945). A preocupação do Nationalsozialistische Deutsche Arbeiterpartei, o partido nazista, em angariar adeptos entre os jovens inspirou esmero nas estratégias de cooptação de crianças e adolescentes. Na Alemanha, conforme Susan Bartolleti, "os nazistas sabiam do que as crianças gostavam - de uniformes, bandeiras, bandas de música, distintivos, armas e histórias de heróis - e ofereciam tudo isso em quantidade”1.

\footnotetext{
1 BARTOLETTI, Susan Campbell. Juventude hitlerista: a história dos meninos e meninas nazistas e a dos que resistiram. Trad. Beatriz Horta. Rio de Janeiro: Relume Dumará, 2006. p.14 e p. 31.
} 
Décadas depois, explorando a rede mundial de computadores, o movimento neonazista atualizou este processo de sedução.

Aliás, a combinação de apelo à tradição - representada por distintivos, flâmulas, rituais de iniciação, cânticos, etc. - com elogios à tecnologia cimentou as propagandas fascistas desde a década de $1920^{2}$. Embora aparentemente contraditória, esta proposta encontra amparo no fato de que, se, por um lado, o fascismo "ao mesmo tempo em que critica violentamente o tempo presente e constrói uma utopia regressiva voltada para o passado”, por outro, “não hesita em lançar mão dos meios mais avançados do ponto de vista tecnológico para difundir o ódio ou realizar seu domínio sobre a sociedade”3.

No século XXI, a emergência do chamado "hate speech" no ciberespaço ofereceu a possibilidade de aproximar extremistas, permitindo-lhes maior articulação ${ }^{4}$. Apesar da dificuldade em classificar a imensa variedade de grupos existentes, podemos acompanhar a conceituação de "neofascistas" ou extremistas de direita, considerando os seguintes traços, identificáveis em todos eles: 1. retórica de unidade racial, nacional e destino comum; 2. convicção de um status quo ameaçado; 3. ideias de supremacia racial; 4. visão de mundo de utopia revolucionária que busca derrubar a ordem existente; 4. antiliberalismo; 5. anticomunismo; 6. ódio ao outro conveniente que pode ser o judeu, em âmbito universal, mas que apresenta variações em esferas locais (nordestinos, gays, mulçumanos, latinos).

A composição desta "family of resemblances" 5 - que incorpora os aspectos básicos apontados por Franz Neumann ao descrever o Estado nazista, como Behemoth, e Ernest

\footnotetext{
${ }^{2}$ Robert Paxton nos lembra coisas, como a nostalgia rural alimentada pela propaganda fascista, da qual o Duce de peito nu em meio à colheita é talvez o melhor exemplo, que contrastavam com o culto às máquinas: "Os líderes adoravam seus carros, aviões velozes e difundiam sua mensagem usando técnicas de propaganda e de cenografia fulgurantemente modernas”. PAXTON, Robert. A anatomia do fascismo. Trad. Patrícia Zimbres e Paula Zimbres. Rio de Janeiro: Paz \& Terra, 2007.p.30

${ }^{3}$ SILVA, Francisco Carlos Teixeira da. O debate do Holocausto como paradigma da intolerância. In: Revista Eletrônica Carta Maior. < www.cartamaior.com.br> Acesso em: 28 mar. /2008; disponível também via <http://www.tempopresente.org/index.php?option=com_content\&task=view\&id=1467\&ltemid=124> Acesso em: 29 mar. 2008.

4 BACK, L; KEITH, M; SOLOMOS, John. Racism on the Internet: mapping neofascist subcultures in cyberspace. BJØRGO, T.;KAPLAN, J. (Orgs.). Nation and race: the developing Euro-American racista subculture. Austin, TX: Northeastern University Press, 1998. p.73.

${ }^{5}$ Para uma discussão sobre os fascismos ver: SILVA, Francisco Carlos Teixeira da; VIANA, Alexander Martins. Dicionário crítico do pensamento da direita: ideias, instituições e personagens. Rio de Janeiro:
} 
Nolte e a sua noção de um "mínimo fascista" -, envolta em anticomunismo, antiliberalismo, antiracionalismo e anticonservadorismo não desconsidera a diversidade de culturas de extrema-direita, mas compreende um esforço para analisar também as possíveis variações do racismo, do antissemitismo, da homofobia e de outras manifestações de ódio ao outro através dos usos das novas tecnologias ${ }^{6}$.

Para entender tal fenômeno, algumas perguntas iniciais guiam este texto: 1. Como se têm usado os meios virtuais entre os ativistas de extrema-direita? 2. Há especificidades quando observamos Brasil e Argentina, as duas mais influentes nações da América do Sul? 3. Houve algum tipo de material preferencial para a difusão via rede? 4. A internet e a emergência das redes sociais têm contribuído para a criação de uma visão global ou isto acentuou os localismos? 5. É possível identificar conexões entre os grupos estudados?

Considerando que a tecnologia não possui uma ideologia particular, nossa proposta é proceder a uma análise política dos extremismos de direita, considerando os meios nos quais as suas ideias são veiculadas. Desta maneira, estamos colocando em destaque e comparando as modalidades culturais na prática fascista. No Brasil, entre os divulgadores do ódio e da supremacia racial na web merece menção o Valhalla. Criado em 1997 e retirado de operação em 2007, através de ação judicial e de parceria entre a polícia brasileira e a argentina, o site já esteve instalado no provedor argentino Ciudad Libertad de Opinión (www.libreopinion.com) - provavelmente o maior hospedeiro sul-americano de páginas da extrema-direita. No Valhalla era possível encontrar textos de conhecidos revisionistas como Robert Faurisson e Bruce Hagen.

Desde as primeiras manifestações cibernéticas, ainda no final da década de 1990, as ideias destes grupos eram veiculadas com estratégias de simplificação (através de slogans, por exemplo), da construção de um inimigo único, o outro conveniente que, como observou Robert Paxton, compreende uma variável que pode ser o negro, o

FAPERJ/Mauad, 2000; NEUMANN, Franz. Behemoth: the structure and practice of national socialism, 1933-1944. Chicago: Ivan R. Dee/United States Memorial Museum, 2009; KERSHAW, Ian. Hitler, the Germans, and the final Solution. London/Yale University Press, 2008; PAXTON, Robert. A anatomia do fascismo. Trad. Patrícia Zimbres e Paula Zimbres. Rio de Janeiro: Paz \& Terra, 2007.

${ }^{6}$ BACK, L.; KEITH, M.; SOLOMOS, John. Racism on the Internet: mapping neofascist subcultures in cyberspace. BJØRGO, T., KAPLAN, J. (Orgs.). Nation and race: the developing Euro-American racista subculture. Austin, TX: Northeastern University Press, 1998. p.76. 
nordestino, o homossexual e, frequentemente, o judeu? ${ }^{7}$ Portanto, entre 1999 e 2007, grupos sul-americanos de extrema-direita, com diferentes matizes, demonstraram as potencialidades da rede mundial de computadores.

\section{História digital: a pesquisa em tempos de internet}

A abertura da web para o mundo, sua ocupação por não-especialistas, proporcionada pela Word Wide Web, marca um novo tempo. Nele, como ponderou Manuel Castells, economias, atividades culturais, políticas governamentais, empreendimentos comerciais, procedimentos e políticas de saúde são pensados a partir da sua inserção na web ${ }^{8}$. Daí a relevância em refletir sobre o futuro da arte de preservar o passado. Vivemos uma impressionante transformação. Em meio à avalanche de registros, a inevitável pergunta: o que preservar?

Até pouco tempo, eram grandes as dificuldades para publicar um artigo, torná-lo conhecido e acessível, publicar um livro ou manter contato com as fontes. Como observa Roy Rosenzweig ${ }^{9}$, a internet mudou este quadro de modo significativo. Em lugar de uma cultura da escassez, o historiador precisa aprender a lidar com a cultura da abundância.

Para este ensaio, um importante locus de pesquisa foi 0 endereço http://www.internetarchive.org. Ali, através da ferramenta eletrônica www.waybackmachine.org, pudemos acessar inúmeras de páginas dos grupos selecionados para a análise, as quais, após denúncias e ações policiais, foram retiradas de funcionamento. Neste imenso "arquivo" virtual, muitas páginas não se mostraram completas, sendo comuns links sem funcionamento e até ausência de imagens. Certas páginas não foram encontradas; alguns registros foram apagados e, possivelmente, jamais voltarão a ser vistos (a menos que algum site emulador da extrema-direita deles tenha feito backup ).

\footnotetext{
7 PAXTON, Robert. A anatomia do fascismo. Trad. Patrícia Zimbres e Paula Zimbres. Rio de Janeiro: Paz \& Terra, 2007.

${ }^{8}$ CASTELLS, Manuel. A Galáxia Internet: reflexões sobre a Internet, os negócios e a sociedade. Trad. Maria Luiza X. Borges. Rio de Janeiro: Jorge Zahar Ed., 2003. p.11.

${ }^{9}$ ROSENZWEIG, Roy. Scarcity or Abundance? Preserving the past. In: Clio Wired: the future on the past in the digital age. New York: Columbia University Press, 2011.p.3-27
} 
Neste aspecto, nossa experiência é semelhante à dos investigadores que se interessam por jornais do século XVIII ou XIX. Nenhuma destas dificuldades deve ser motivo para justificar o distanciamento do historiador nem as eventuais tentativas de desqualificar seu trabalho ao lidar com sítios eletrônicos. O que é preciso, neste caso, é ter atenção aos procedimentos de crítica histórica ${ }^{10}$. A crítica não deve diferir das adotadas pela análise histórica clássica. Como lembra Antoine Prost, "trata-se do mesmo método, aplicado a outra documentação que, às vezes, utiliza saberes específicos"11.

A partir do ciberespaço, deve-se não apenas identificar aquilo que é representado, mas também considerar o comportamento e as possíveis "fabricações" dos frequentadores da rede mundial de computadores, sendo fundamental refletir sobre as práticas sociais ali elaboradas ${ }^{12}$. Todavia, é preciso logo desmontar a frágil ilusão de dominar este novo locus de produção e distribuição de fontes. Lidamos com um objeto de capacidade de mutação talvez inédita. E, justamente por isto, precisamos ter em conta que o estudo não terá como esgotar as fontes de informação disponíveis, pois, como afirmou Manuel Castells, a rede "se desenvolve e muda muito mais depressa que o sujeito", ou seja, o pesquisador ${ }^{13}$.

Ao enfrentaruma documentação que parece revelar tudo e é, ao mesmo tempo, fugidia, "líquida”, será estratégica a observação do pormenor revelador ${ }^{14}$. A busca será por "zonas privilegiadas", por "sinais", por pistas que contribuam para a reflexão. Na teia mundial de computadores, devemos aprender a rastrear "indícios" com os quais pensar o passado. Espera-se, deste modo, apreender não apenas os projetos propostos pelos conteúdos dos web sites, mas sobretudo seus usos, apropriações e formas de consumo empregadoss por seus frequentadores ${ }^{15}$. Desta maneira, ao buscar reconstruir formas de

\footnotetext{
${ }^{10}$ BLOCH, Marc. Apologia da História ou O Ofício do Historiador. Rio de Janeiro: Jorge Zahar Editor, 2001.

${ }^{11}$ PROST, Antoine. Doze lições sobre história. Tradução Guilherme João de Freitas Teixeira. Belo Horizonte: Autêntica Editora, 2009. p. 64.

${ }^{12}$ CERTEAU, Michel de. A Invenção do cotidiano: artes do fazer. Trad. Ephraim Ferreira Alves. Petrópolis, RJ: Vozes, 1994. p. 34.

${ }^{13}$ CASTELLS, Manuel. A Galáxia Internet: reflexões sobre a Internet, os negócios e a sociedade. Trad. Maria Luiza X. Borges. Rio de Janeiro: Jorge Zahar Ed., 2003. p. 11.

${ }^{14}$ BAUMAN, Zygmunt. Globalização: as consequências humanas. Trad. Marcus Penchel. Rio de Janeiro: Jorge Zahar Editor, 1999.

${ }^{15}$ GINZBURG, Carlo. Sinais: raízes de um paradigma indiciário. In: Mitos, emblemas e sinais: morfologia e história. Trad. Frederico Carotti. 2. ed. São Paulo: Companhia das Letras, 1989. p. 143-180.
} 
ação, mudanças e representações construídas no passado a partir de um ambiente como a internet, poderemos ampliar os debates sobre a inserção do mundo digital em nossas vidas, em nossa história.

\section{Sobre história comparada}

No que concerne ao aporte metodológico, nos valeremos da História Comparada. Em História, o que é comparar? Em artigo considerado um dos textos fundadores deste tipo de abordagem, Marc Bloch escreveu que comparar seria:

faire choix, dans une ou plusieurs milieux sociaux, différents de deux ou plusieurs phénomènes qui paraissent, au premier coup d'oeil, présenter entre eux certaines analogies, décrie les courbes de leurs évolutions, constater les ressemblances et les différences et, dans la mesure du possible, expliquer les unes et les autres" ${ }^{\prime 16}$.

O autor foi um dos defensores mais conhecidos do comparatismo, talvez seu maior divulgador. Tendo enfrentado os tenebrosos desdobramentos dos nacionalismos oriundos do século XIX, quando se viu combatente na I Guerra Mundial, identificou no comparatismo o método ideal para evitar localismos e, desta maneira, fugir do diálogo de surdos entre os pesquisadores dos fenômenos nacionais que tanto o incomodavam.

Em seu texto, Por une Histoire Comparée de sociétés européennes (Por uma História Comparada das sociedades europeias), advoga a viabilidade do método comparativo ao argumentar: “Ce qu'il demande à une méthode, c'est d'être un instrument technique, d'usage courant, maniable et susceptible de résultats positifs" ${ }^{17}$. O método comparativo atende a estes requisitos. $\mathrm{O}$ autor distingue dois tipos fundamentais de comparação:

1) aquele que apresenta similitude entre os fatos observados - se elegem sociedades separadas no tempo e no espaço por distâncias tais que as analogias, observadas em uma e outra parte, entre um fenômeno e outro, não

\footnotetext{
${ }^{16}$ Em tradução livre do autor: "fazer escolhas, em uma ou mais situações sociais diferentes, de dois ou mais fenômenos que parecem à primeira vista, para apresentar algumas analogias entre eles, descrever as curvas de seus desenvolvimentos, ver semelhanças e diferenças e, na medida possível, explicá-los mutuamente". BLOCH, Marc. Por une Histoire Comparée des societies européennes. In: Revue de Synthèse Historique. 46:15-50. p.17.

${ }^{17}$ Em tradução livre do autor: "O que ele pede é um método para ser um instrumento técnico, de uso comum, acessível e capaz de resultados positivos.” Ibid., 46:15-50. p.16.
} 
se possam explicar, evidentemente, nem por influências mútuas, nem por comunidade de origem;

2) estudar sociedades às vezes vizinhas e contemporâneas, constantemente influenciadas umas pelas outras, submetidas, em seu desenvolvimento, precisamente por suas proximidade e seu sincronismo, à ação das mesmas grandes causas, provenientes, ao menos parcialmente, de uma origem comum $^{18}$.

O autor de Os Reis Taumaturgos - um ensaio de história comparada sobre as monarquias da França e da Inglaterra ${ }^{19}$ - define a sua preferência pelo segundo modelo. Para Bloch, o segundo método comparativo - o que observa sociedades próximas e sincrônicas -, é o mais limitado em seu horizonte, mas também cientificamente ${ }^{20}$ o mais rico. Tal expediente metodológico se mostra adequado à investigação apresentada neste texto.

Todavia, se comparação implica procedimento de seleção, abstração, ela também necessita de descontextualização. Não para livrar-se da análise, mas para desnaturalizá-la, para aprofundá-la. Deste modo, abordagens comparativas apenas enfatizam e, provavelmente, ajudam a manifestar o que se encontra implícito em todo tipo de trabalho histórico: um forte componente seletivo e construtivo, como apontou Kocka ${ }^{21}$.

É a unidade do problema que deve interessar ao historiador, não apenas as limitações impostas pela geografia. Ao recortar determinada sociedade para estudo, é preciso levar em conta a sua "integridade histórica" para que assim seja possível realizar o duplo movimento de buscar a totalidade sem incorrer em generalizações. A busca de generalizações não deve ser o fio condutor do trabalho do historiador, pois este "não constrói suas análises a partir de modelos elaborados a priori”22.

\footnotetext{
${ }^{18}$ Ibid., 46, p.17- 19

${ }^{19}$ Id. Reis Taumaturgos - o caráter sobrenatural do poder régio: França e Inglaterra. Pref. Jacques Le Goff. Trad. Júlia Mainard. São Paulo: Cia das Letras, 2ª reimp., 1999.

${ }^{20} \mathrm{BLOCH}$, Marc. Por une Histoire Comparée des societies européennes. Revue de Synthèse Historique. p.19

${ }^{21}$ KOCKA, Jürgen. Comparison and beyond. History and Theory, Vol. 42, No. 1 (Feb., 2003), p.44

${ }^{22}$ PRADO, Maria Ligia Coelho. Repensando a história comparada da América Latina. Revista de História. Universidade de São Paulo, n. ${ }^{\circ} 153,2005$, p.11-33.

DA AMÉRICA LATINA . Revista de História , n.153 (2º - 2005), 11-33, p. 22
} 
O produto deste método deve colaborar, portanto, para uma iluminação recíproca, para uma abordagem que se pretenda solidária. A justaposição de interpretações e dados deve ser a todo custo evitada ${ }^{23}$. Considerando a riqueza da observação, em perspectiva comparada, de Brasil e Argentina, acreditamos ser tal método proveitoso.

\section{Ciberespaço: arena política do século xxi}

Os ativistas de extrema-direita ganharam destaque, em primeiro lugar, pelo uso pioneiro que fizeram do ciberespaço. Percebendo a economia e a agilidade das redes, logo pôs as mãos nos teclados. Ainda nos primeiros anos da internet comercial, em 1996, o "Times" noticiava as páginas do ódio em franca ascensão: "racists have discovered that the Net is a marvelous way to get their message out to a huge audience at low cost" 24 . Com a ocupação do ciberespaço, era possível evitar o muitas vezes perigoso contato frente-a-frente. Na era eletrônica, a capacidade dos grupos domésticos em países como EUA para a constituição de parcerias internacionais se ampliou significativamente com o apoio de computadores, mas também de ferramentas como o Fax e de recursos como a editoração eletrônica.

A simples ideia de que qualquer pessoa pode expressar a sua visão de mundo para uma imensa massa contribuiu significativamente para o desenvolvimento de extremismos on line. Explorando o potencial da internet, os divulgadores de ideias de ódio racial intensificaram a sua capacidade de atuação no mundo real. Ao contrário de outros tempos, não são mais panfletos mimeografados ou fotocopiados. Agora, são homepages sofisticadas e com forte apelo visual. As marchas militares da SS (Schutzstaffel), a tropa de elite nazista, depois de sampleadas, deram origem ao "nazi-techno" de canções como “Adolf Hitler Party (Swastika Mix)”, do DJ Adolf. Uma destas músicas parodia "The Battle Hymn of the Republic", hino cívico-religioso de 1861, popularizado na Guerra de Secessão

${ }^{23}$ BARROS, José D'Assunção. História Comparada - um novo modo de ver e fazer história. Revista de História Comparada. Junho 2007, v.1, n.1,p.23

24 "Racistas descobriram que a Net é uma forma maravilhosa de levar sua mensagem a um público enorme a baixo custo". Tradução livre. QUITTNER, Joshua, STAMPER, Chris. Home pages for hate. Time. Jan. 22, 1996. <www.time.com/time/.../o,9171,983994,oo.html >Último acesso: 20 ago. 2011. 
dos Estados Unidos (1861-1865) ${ }^{25}$. Via internet, passou a ser possível comprar discos de bandas como Racist Rednecks Rebels, ou simplesmente fazer o download em MP3 de canções raivosas como as do grupo brasileiro Brigada $\mathrm{NS}^{26}$, ou da Rahowa, em cuja faixa "Third Reich" se ouvia "You kill all the niggers and you gas all the jews/Kill a gypsie and a commie too"27.

\section{1 intolerância.com.ar}

Acompanhando este movimento, em 21 de setembro de 1999, em pleno processo de explosão da internet, apareceu o portal argentino “Ciudad Libertad de Opinión” (http://www.libreopinion.com), dono do IP 190.228.30.234, registrado em Buenos Aires. Em pouco tempo, a página se tornou o mais conhecido sítio sul-americano de extremadireita, hospedando grupos bolivianos, chilenos, equatorianos, peruanos, brasileiros, argentinos e venezuelanos. Alguns Skinheads White Power brasileiros escreveram, em ingles, em sua página: “Obrigado, Libre Opinion, por respeitar nossas opiniões e hospedar a nossa página". De cada um dos sítios hospedados pelo LO disparavam-se discursos furiosos. Cada um deles foi, durante anos, porta-voz da intolerância. 25 "My eyes have seen the glory of the trampling at the zoo,/We washed ourselves in niggers blood and all/
the mongrels too,/We're taking down the Zog machine jew by jew by jew,/The white man marches on".
DJ Adolf. $\quad$ The mante marches <http://www.autolyrics.com/lyrics/for/The_White_Man_Marches_On/by/American_History_X> acesso em: 20 mar. 2008.

${ }^{26}$ Eis algumas bandas declaradamente fascistas dedicadas ao "White Metal" - subgênero do Heavy Metal, gênero musical derivado do hard rock inglês - pelo mundo: no Brasil - Command, Corrosão, Defesa Armada, Goat Penis, Grupo Separatista Branco, Locomotiva 88, Resistência 88 e Thallium; na Argentina Accion Radical, Comando Suicida, Nuremberg, Razon y Fuerza e Ultrasur; no Chile - Odal Sieg; em Portugal - Guarda de Ferro e Lusitanoi; na Espanha - British Standard; Nemesis; Itália - SPQR; Intolleranza; Hungria - Junkers 88; na Inglaterra: White Law; Avalon, Blackshirts; na França - Kontingent 88 Kristallnacht; Legion 88; na Rússia - Totenkopf; Terror National Front; na Polônia: Falanga 88; Swastyka; Zyklon B e na Alemanha - Reichssturm, Eugenik, War 88. White POWER Music Groups <http://www.adl.org/learn/Ext_US/music_country.asp> Acesso em: 15 mar. 2008.

${ }^{27}$ Tradução livre nossa: "Você mata todos os negros e você 'gaseifica todos os judeus / Mata um cigano e um comunista também". Rahowa é a saudação dos fiéis da World Church of the Creator, derivação da Church of the Creator criada por Ben Klassen, um norte-americano da Flórida, filho de imigrantes alemães, que se suicidou em 1993. A seita foi remodelada pelo reverendo Matt Halle, de Illinois, EUA. A saudação é o acrônimo da expressão "Racial Holy War", isto é "Guerra Santa Racial”, que prega a eliminação dos "inimigos naturais" - negros, mestiços, judeus, comunistas, homossexuais. A WCOTC ganhou espaço graças ao uso da internet. O reverendo Halle investiu no ciberespaço e colheu frutos significativos. Segundo ele: "A internet tem o potencial para atrair milhões de brancos com nossa mensagem e nós precisamos utilizar isso sem entremeios". Cf. NEONAZISMO web (I): Radiografia do templo do ódio<http://www.abknet.de/wcotc.htm> Acesso em: 22 out. 2005. 
Porém, através de ação da Justiça brasileira e de parceria entre as polícias federais dos dois países, em 2007 o portal argentino viu-se forçado a excluir sites produzidos por brasileiros. Entre os desativados, podemos identificar, por exemplo, páginas como Valhalla 88, White Power SP, Blood and Honour Southland, White Honour. No entanto, ao retirarem estes sítios de operação, as autoridades conseguiram apenas uma vitória parcial. As ideias de ódio e intolerância não perderam espaço, sobretudo pelo fato de que os mesmos grupos já se haviam movimentado para espalhar mais ainda as suas ações, explorando servidores de fora da América do Sul e, na maioria das vezes, migrando para as redes sociais, emergentes a partir de 2003.

Os casos acima evidenciam que ao final do século XX uma rede virtual de grupos de extrema-direita foi montada com o auxílio da internet. Entre 1999 e 2007, a maioria das páginas sul-americanas deste tipo aparecia alojada no Ciudad Libertad de Opinión. O sítio argentino funcionou como um portal, agregando diferentes tipos de homepages, oferecendo links, opções de atividades, soluções para operações clandestinas e violentas, articulando uma proposta de ação conjunta e dispersa ao mesmo tempo.

\subsubsection{Os nazis argentinos vão para a rede}

O Ciudad Libertad de Opinión foi criado pelo ativista argentino Alejandro Carlos Biondini, líder do Partido Nuevo Triunfo (PNT), antigo Partido dos Trabalhadores, um subproduto político da ultradireita peronista ${ }^{28}$. A opção de Biondini pela internet foi estratégica. Seu partido, oficialmente criado em 1990, não ganhou o espaço pretendido, além de suas propostas claramente inspiradas no fascismo alemão the haverem rendido em ações na Justiça. ações na Justiça. Portanto, a migração para a rede mundial de computadores pode ser explicada pela ideia de que estabelecer-se na rede era a oportunidade para sugerir ao Partido Nuevo Triunfo dimensões que não possuía.

Desde o final dos anos 1990, a página foi a principal articuladora entre vários grupos extremistas sul-americanos. Através do portal, por exemplo, era possível chegar ao sítio brasileiro do Combat 18, conhecido grupo neonazista. Ali, os fóruns reuniam

\footnotetext{
${ }^{28}$ KOLLMANN, Raúl. Sombras de Hitler: la vida secreta de las bandas neonazis argentinas. Editorial
} Sudamericana: Buenos Aires, 2001.p.101 
curiosos, a maior parte deles ardorosos defensores da intolerância. Assim, motivando e tentando coordenar ações de grupos em várias partes do mundo, o sítio Ciudad Libertad de Opinión atuou livremente entre 1999 e 2007, quando passou a enfrentar ações de governos, como o brasileiro, que conseguiram identificar alguns dos responsáveis por páginas lá hospedadas e exigir que fossem punidos. Embora antes da popularização da internet grupos extremistas de direita já mostrassem força com ações no Brasil e na Argentina, a instalação de organizações francamente inspiradas por ideias fascistas no ciberespaço demarca uma iniciativa nova, ainda carente de reflexões.

\subsubsection{El pequeño Führer}

Quem é Alejandro Biondini? Filho de um líder comunista e mãe católica, antissemita confesso, Alejandro Carlos Biondini nasceu em 12 de janeiro de 1956, em Buenos Aires. Segundo ele mesmo informa, desde cedo se preparou para liderar a Argentina. Atuou na juventude peronista, foi voluntário nas Malvinas em 1982 e em 1983 fundou o Alerta Nacional, embrião do futuro Partido Nacionalsocialista de los Trabajadores, criado em maio de 1990, com perspectiva nazi ortodoxa; isto é, a organização se propunha ser um êmulo do original nazista criado na Alemanha nos anos 1920.

Proibido de usar a denominação "nacional-socialista", Biondini rebatizou o grupo de Partido Nuevo Triunfo (PNT). Após tentativas de realizar marchas, ainda em 1990, o político foi preso por propaganda nazista, quando afixou a suástica no prédio do Congresso argentino e em áreas do centro portenho. Ao ferir a lei $23.592^{29}$, o ativista, apelidado ironicamente pela imprensa do país de "pequeño führer", ficou na cadeia por 200 dias.

\footnotetext{
${ }^{29}$ Conforme a legislação argentina, Biondini feriu, no mínimo, a Ley 23.592, em seu artigo 3, que explicita, conforme tradução livre: "Serão punidos com pena de prisão de 1 mês a 3 anos, aqueles que participarem de uma organização ou realizarem a propaganda baseada em ideias ou teorias de superioridade de uma raça ou grupo de pessoas com uma religião certa, etnia ou cor, justificação destinada ou promover a discriminação racial ou religiosa, sob qualquer forma. A mesma pena incorrerá a quem por qualquer meio alimentar ou incitar perseguição ou ódio contra qualquer pessoa ou grupo de pessoas por causa da sua raça, religião, nacionalidade ou convicções políticas". <http://www.apadeshi.org.ar/leyantidicriminacion.htm> Acesso em: 20 nov. 2012.
} 
Fazendo questão de ter o nome ligado a Péron, a Franco e à luta contra os ingleses nas Malvinas, Biondini alimenta certo mistério em torno da sua trajetória. Um deles diz respeito à sua suposta predestinação como líder para comandar a ressurgência nazista. Segundo sugere, o próprio Hitler, no eclipse do III Reich, olhando o mapa do mundo teria apontado para a Argentina afirmando que dali sairia o seu verdadeiro sucessor ${ }^{30}$. 0 político argentino envolve-se, propositalmente, numa aura de mistério e deixa fáceis pistas aos seguidores, como o número da sua inscrição no PNT - número 7 -, assim como o do seu ídolo alemão. É também assim, em cerimônias de iniciação que ocorrem nos dias 7 de agosto, dia de São Caetano, 7 ho7 da noite, nas quais 7 novos "iniciados" são incorporados ao grupo ${ }^{31}$.

A “cruz de São Caetano" utilizado como um dos seus símbolos oficiais é interpretada como a representação do “crislam”, já que incorpora a cruz católica e a meia-lua islâmica. Em síntese, seria um ícone da aliança entre cristãos e mulçumanos contra o judaísmo. Além disto, Biondini utiliza o mesmo recurso para uma definição mística, "Kalki", com que se faz chamar pelos seguidores e entre os internautas. Kalki é a décima e última encarnação de Vishnu, aquele que, conforme a mitologia hindu, virá para colocar fim à era de trevas ${ }^{32}$. Além de uma evocação do líder como um deus, o PNT apresentou inicialmente o mesmo slogan do seu inspirador germânico: “Un Pueblo, una Nácion, un líder”, tal qual "Ein volk, Ein Reich, Ein Führer” do NSDAP33. O dia oficial de criação do PNT é 20 de abril, data em que também nasceu Adolf Hitler.

Em 2004, o Partido Nuevo Triunfo teve negada sua solicitação de registro como partido em condições de participar das eleições argentinas. Biondini chegou a suavizar o discurso no programa da organização entregue para avaliação da Justiça Eleitoral. Porém,

30 KOLLMANN, Raúl. Sombras de Hitler: la vida secreta de las bandas neonazis argentinas. Editorial Sudamericana: Buenos Aires, 2001.p.23.

31 KOLLMANN, Raúl. Sombras de Hitler: la vida secreta de las bandas neonazis argentinas. Editorial Sudamericana: Buenos Aires, 2001.p.21

32 KOLLMANN, Raúl. Sombras de Hitler: la vida secreta de las bandas neonazis argentinas. Editorial Sudamericana: Buenos Aires, 2001.p.22

33 Tanto para o espanhol quanto para o alemão: “Uma nação, um povo, um líder”. Tradução livre do autor. Cf. KOLMANN, Raúl. Los neonazis usan maquilaje. Página 12. 24 dic.2003. Acesso em 20/07/2012. <http://www.pagina12.com.ar/imprimir/diario/elpais/1-29682-2003-12-24.html>. Ver ainda: KOLMANN, Raúl. Un parate legal para el partido del pequeño führer. Página 12. 20 de oct. 2003.

<http://www.pagina12.com.ar/imprimir/diario/elpais/1-27043-2003-10-20.html>. Acesso em 20/07/2012. 
Secretaría de Derechos Humanos, na época dirigida por Eduardo Luis Duhalde, e o Instituto Nacional contra la Discriminación (Inadi), que assim se pronunciou sobre o pleito:

\begin{abstract}
"Exaltan la violencia, exhortan al odio contra quienes son miembros de la comunidad judía nacional e internacional, como así también reivindican al líder nazi Adolfo Hitler, las insignias del partido Nacional Socialista Alemán, todo ello en franca contradicción con los valores democráticos" ${ }^{34}$.
\end{abstract}

Os resultados de apontamentos como os do Inadi motivaram a decisão judicial negativa, impedindo assim ao partido de ganhar espaço para seu discurso xenófobo que, embora frouxamente disfarçado no texto impresso entregue para sua regularização, foi mantido na íntegra na internet ${ }^{35}$. Enquanto apresentou um documento impresso que posicionava o grupo como contrário a "todo tipo de racismo y antisemitismo" e deixava de lado o uso da suástica (de acordo com a ata 8/2003 do partido), Biondini e seguidores continuaram a vociferar, através da página Libre Opinión, a sua retórica fascista. A página do PNT, que continuava a acusar a existência de uma "rede homossexual argentina", classificava os judeus como "criminosos de guerra, torturadores, usurários, raça de víboras" $"$.

O PNT teve nova solicitação de registro recusada pela Cámara Nacional Electoral e pela Suprema Corte da Argentina, que, conforme o Clarín de 17 de março de 2009, considerou: "No se pueda legitimar como partido político a quienes incurren en apología

\footnotetext{
${ }^{34} \mathrm{Em}$ tradução livre: "Exaltam a violência, exortam o ódio contra os que são membros da comunidade judaica nacional e internacional, bem como reivindicam o líder nazista Adolf Hitler, as insígnias do Partido Nacional Socialista Alemão, tudo isto em clara contradição com os valores democráticos". KOLMANN, Raúl. A loz nazis les dicen "nein". Página 12. 7 feb. 2004. <http://www.pagina12.com.ar/imprimir/diario/elpais/1-31220-2004-02-07.html>. Acesso em: 20 jul. 2012.

${ }^{35}$ Ver texto de KOLMANN, Raúl. LA JUSTICIA NO ACEPTO LEGALIZAR AL PARTIDO NAZI. Página 12. 10 mai. 2004. In: Argentina: un giudice nega la legalizzazione di un partito neonazista. http://www.peacelink.it/latina/a/4881.html. Acesso em: 12 set.2012.

36 KOLMANN, Raúl. Los neonazis usan maquilaje. Página 12. 24 dic.2003. Acesso em: 20 jul. 2012. <http://www.pagina12.com.ar/imprimir/diario/elpais/1-29682-2003-12-24.html>.
} 
del odio e, indirectamente, incitan a la violencia" ${ }^{37}$. Ao final do século XX, a migração de suas operações para a rede mundial de computadores foi a alternativa encontrada para tentar angariar mais adeptos. A partir do novo fracasso em obter a legalização do PNT, Biondini/Kalki direcionou seus esforços para a ampliação do então Portal Ciudad Libertad de Opinión, como uma espécie de versão virtual do partido. Através do sítio, a netkrieg (uma guerra em rede inspirada no modelo coordenado da blitzkrieg) começou. Alardeando guiar-se pelos princípios éticos “Deus, Pátria, Justiça Social e Família”, o Libre Opinión passou a oferecer aos internautas, desde seus primeiros momentos na rede, fartas opções de navegação: fóruns, jogos on line, informações sobre a Argentina e países vizinhos através da Agencia de Noticias RED KALKI, ou do Tablero de Anuncios.

\subsubsection{O Panteão}

Entre as notícias, aparecem manipulações como aquelas referentes às mortes dos “mártires” do partido - Luis Alberto Vera, Alfredo Guereño e René Túlian. O primeiro teria sido morto em um ritual judeu, no qual the haveriam retirado todo o sangue e, em seguida, joga o seu corpo do nono andar no fosso de um elevador; Vera teria sido assassinado a $\operatorname{tiros}^{38}$ sem explicação alguma; Túlian, atropelado, chegou lúcido ao hospital, teria sido envenenado por um médico judeu ligado à DAIA ${ }^{39}$ (Delegación de Asociaciones Israelitas Argentinas, Delegação de Associações Israelitas Argentinas). Todavia, fora da fantasia dos neonazis, as mortes ganham contornos diferentes a respeito da tal conspiração judia.

Por exemplo, a morte René Túlian, vice-presidente do PNT, que recebeu narrativa espetacular, não encontra amparo nos registros médicos, que evidenciam os exageros e a apropriação da morte acidental do ativista. Conforme Raúl Kollmann, Túlian realmente morreu no Hospital Argerich, mas várias horas depois da sua entrada, não minutos, como afirmava o "panteão eletrônico" do PNT. "No lo atendió un médico judio, sino la doctora

\footnotetext{
${ }^{37}$ Em tradução livre: “ Não se pode legitimar como partido político aquele que incorra na apologia ao ódio e, indiretamente, incite à violência”. La Corte Suprema le negó la personería jurídica a un partido nazi. http://edant.clarin.com/diario/2009/03/17/um/m-01879057.htm

${ }^{38}$ Ver: http://web-beta.archive.org/web/20040615155657/http://pnt.libreopinion.com/vera.htm Acesso em: 20 dez. 2011.

39 Id. ibid.
} 
Lucrecia Valdez. El acidentado tenía politraumatismo, traumatismo craneoencefálico grave y fractura leve del occupital. Ingresó en coma y sin reflejos". Devido ao seu quadro na chegada ao hospital, pode ter recebido algum reanimante, porém, a autópsia não detectou nenhuma substância tóxica ${ }^{40}$.

Ao que tudo indica, o mito da "punhalada pelas costas", alimentado por Biondini, foi recorrentemente utilizado pelo Libre Opinión. A tentativa de formação de uma espécie de "Panteão" de heróis caídos sinaliza isto. Todavia, considerando a existência de mais de duas décadas do grupo, surgido ainda nos anos 1980, a sua parca penetração entre eleitores argentinos evidencia o fracasso das tentativas de fazer crescer o movimento.

Através do site e dos comunicados radiofônicos, Kalki divulga um discurso xenófobo e antissemita, critica partidos de esquerda e tudo que lembre o comunismo. Porém, mais do que o discurso do "pequeno führer", a ação do LO deve ser pensada pela capacidade que o portal concedeu a pequenos grupos da América do Sul de estabelecer intercâmbios. Em uma época de redes sociais gratuitas inexistentes, nos dias da internet 1.o, quando o Google não funcionava ainda como o grande oráculo do cibermundo, o portal idealizado por Biondini alimentou a intolerância. Sendo assim, os seus efeitos não devem ser buscados apenas nos vetores do sucesso ou da derrota eleitoral, mas exigem reflexão sobre as ramificações, as trocas de material possibilitadas pelo sítio argentino a fascistas de vários lugares, a grupos de diferentes tamanhos.

As ações das autoridades contra o site não conseguiram impedir a proliferação de "páginas de ódio" na América do Sul. A chegada da web 2.0 ofereceu novas ferramentas de ativismo. A facilidade para a produção de weblogs, a sedução produzida pelas redes sociais como My Space, Orkut, Youtube, Facebook e, mais recentemente, pelo Twitter, possibilitou um repertório maior e mais sofisticado aos extremistas.

\footnotetext{
${ }^{40}$ Em tradução livre: "Não o atendeu um médico judeu, mas a Dra. Lucrecia Valdez. O acidentado teve politraumatismo, traumatismo craniano grave e fratura occupital suave. Ele ingressou [no hospital] em um coma sem reflexos". KOLLMANN, Raúl. Sombras de Hitler: la vida secreta de las bandas neonazis argentinas. Editorial Sudamericana: Buenos Aires, 2001. p. 109.
} 


\section{2 intolerância.br}

\subsubsection{O Brasil, a rede e os lobos solitários}

A produção de "páginas do ódio" na internet brasileira recebeu apoio estratégico de seus parceiros mundo afora. Dos Estados Unidos, extremistas conhecidos como Nazi Lauck $^{41}$, ofereciam, desde os primeiros momentos de difusão da rede telemática via $w w w$, coordenadas de uso do ciberespaço para a difusão do ódio ao outro. Além disto, o uso dos fóruns do stormfront permitia contatos nos primeiros tempos de popularização da nova rede. Porém, o maior apoio provavelmente veio da Argentina, através do já citado portal Ciudad Libertad de Opinión. Deste imenso ambiente telemático, parte considerável de neonazistas brasileiros conseguiu recursos para colocar no ar as primeiras páginas, para dar visibilidade aos seus endereços eletrônicos, divulgar as suas mensagens, convocar os "camaradas" para a luta, no ciberespaço e fora dele, pela "sobrevivência da raça branca".

A chegada das redes sociais, porém - a maioria delas gratuitas -, mas também o alto padrão de interfaces e de compartilhamento de dados, aliados ao crescente número de denúncias feitas às autoridades de ambos os países colocaram o site argentino em segundo plano para os ativistas brasileiros.

\footnotetext{
${ }^{41}$ Gary "Gerhard" Lauck - Gary Lauck ou Gary "Gerhard" Lauck, um ativista neonazista norte-americano, Fundou o NSDAP/AO (Nazionalsozialistische Deutsche Arbeiterpartei/Auslandsorganisation, "Partido Nacional Socialista Alemão dos Trabalhadores/Organização Exterior"). Apesar de ser uma organização pequena, seu idealizador, que aparece em fotos das internet vestido como um nazi dos anos 1930, ganhou respeito no movimento nacional-socialista mundial. Lauck revela todo o seu ardor com o nazismo e de distancia de influentes setores extremistas norte-americanos por alterar o seu nome de Gary para Gerhard (uma versão germânica). Ele chega a falar inglês com sotaque alemão, além de deixar crescer um bigode semelhante ao de Hitler. Antes de se tornar um líder em seu próprio movimento, Lauck integrou o "National Socialist White People's Party" ('NSWPP - Partido Nacional Socialista do Povo Branco') e, em seguida, o "National Socialist Party of America" ('NSPA - Partido Nacional Socialista da América'). Em ambos os partidos alcançou posições de destaque. Contudo, em 1977, a NSPA enfrentou o escândalo e o descaso depois da descoberta de que o presidente do partido, Frank Collin, era filho de Max Simon Collin (mas de nome original Cohen), um judeu sobrevivente do Campo de Dachau e, além disto, um homossexual pedófilo, fato que se evidenciou por sua prisão em flagrante ao manter relações sexuais com dois garotos de dez anos e a posterior condenação por molestar crianças. Após tamanho revés, Lauck se dedicou totalmente ao "NSDAP/AO". Especializou-se em distribuir propaganda nazista a todo o mundo e se transformou no distribuidor mais importante do movimento nazista internacional. A internet, porém, o desalojou de sua confortável posição, pois os downloads e as trocas de arquivos passaram a ocorrer de modo descentralizado.
} 
Parte significativa dos sites intercambiava material de todo tipo: artigos traduzidos, excertos de discursos de líderes nazistas, pôsteres digitalizados do III Reich, charges contra minorias, fanzines digitais e muita música. O som da intolerância ganhou força no ciberespaço. Aliás, na ausência de um líder que amalgamasse seguidores em ampla quantidade, a música (principalmente o rock e seus subgêneros) foi escolhida para contribuir na sedução dos novos nazistas.

Via internet, usando registros em $\mathrm{MP}_{3}$, era possível compartilhar rápidas lições de ódio ao diferente, de ataque à diversidade, de simplificação da realidade. É o que se pode observar em canções como “Migração”, da banda neonazista brasileira Brigada NS (NS Nacional-Socialista), constante em um álbum intitulado "O retorno da velha ordem": “Dia após dia, migram do Nordeste, centenas de imundos/que são uma grande peste" ${ }^{42}$. E assim, os meninos brancos lutavam ao som do RAC (Rock Against Communism/Rock Contra o Comunismo), subgênero do rock constituído por bandas que abordavam temas atraentes para a extrema-direita, sendo comuns elogios explícitos ao fascismo e ao nazismo. Assumindo uma postura de "denúncia" contra o marxismo, o RAC apareceu no começo da década de 1980, representado principalmente por bandas como a Skrewdriver ${ }^{43}$. Graças ao potencial para atrair jovens às campanhas eleitorais, o som estridente chamava a atenção de setores propagandistas dos partidos de direita.

Em lugar de manifestos elaborados ou de longas e cansativas palestras doutrinárias, os fascistas do ciberespaço trataram de providenciar um material atrativo com jogos eletrônicos, chats e canções que convidavam para a "ação" onde não havia tempo para pensar. Através da web o repertório de recursos para a pregação e a prática da intolerância assumiram dimensões antes inimagináveis por sua velocidade, praticidade e

\footnotetext{
42 BRIGADA NS. O retorno da velha ordem. [São Paulo, Espanha]: Divisão 18, 1998.

${ }^{43}$ Skrewdriver, variação da palavra Screwdriver, isto é, "chave de fenda", esta banda foi uma das mais proeminentes do gênero White Power britânico. Criada pelo inglês lan Stuart Donaldson, suas músicas possuem letras fortemente nacionalistas, xenófobas, racistas, antissemitas e antidemocráticas e se tornaram hinos para a juventude skinhead neonazista de várias partes do mundo. De origem punk, depois de 1978, período em que lan Stuart passou a frequentar as reuniões do National Front, partido da ultradireita inglesa, o preconceito, o chauvinismo e o pensamento conservador progressivamente foram ganhando espaços nas composições do grupo, atraindo uma plateia igualmente intolerante. Em meados da década de 1980, a banda assinou contrato com gravadoras de White Power Music, e tratou de enquadrar o seu estilo ao do RAC (Rock Against Comunism, ver: RAC) e se posicionou abertamente como neonazista.
} 
principalmente baixo custo. Sendo assim, enquanto a rede mundial de computadores ainda ganhava adeptos no Brasil, enquanto o número de computadores no país estava longe dos padrões de países desenvolvidos (tínhamos cerca de 5 milhões em 1998) ${ }^{44}$, os neofascistas se lançavam rapidamente ao manuseio de sítios eletrônicos, aos processos de digitalização, ao cumprimento das exigências da netkrieg. Como Bloch observou diante da derrota francesa frente aos alemães na Segunda Guerra, a velocidade foi a chave para explicar como tudo aconteceu sem que fosse possível impedi-los ${ }^{45}$. Hoje, nos lembra Nye Jr., além da velocidade, um outro fator se alia à rede e ajuda a explicar a sua posição diferenciada: o baixo custo ${ }^{46}$.

\subsubsection{Valhalla à brasileira}

A página brasileira Valhalla $88^{47}$ (I.P 69.73.138.107) e seu conteúdo estiveram facilmente disponíveis entre 1997 e 2007. Após a ação da Polícia Federal e a extinção das atividades do sítio, parte do material nele existente foi disponibilizada pelo portal espanhol Nueva Orden, que, desta forma, passou a ser o principal link de um dos mais ativos sítios da intolerância na América do Sul, reputação obtida principalmente graças ao suporte do seu hospedeiro original, o provedor argentino libreopinion.com. Durante a sua década de operação, seus principais alvos eram negros, judeus, homossexuais, imigrantes e, sobretudo, nordestinos ${ }^{48}$.

O Valhalla 88 ganhou fama na rede pela variedade de material e por ser estável, diferentemente de outros sites que rapidamente desapareciam. Assim, esta regularidade, o "compromisso com a causa”, chamava a atenção dos navegantes. Acrescente-se a isto que, em tempos de web 1.0, das conexões discadas e de simples recursos de compartilhamento, o grupo disponibilizava imagens - fotos, panfletos, pôsteres do III Reich, charges, vídeos, áudio em MP3 -, mas também textos do chamado "revisionismo

\footnotetext{
${ }^{44}$ Para dados oficiais sobre a internet no Brasil, consultar: http://www.cetic.br/

${ }^{45}$ BLOCH, Marc. A estranha derrota. Rio de Janeiro: Zahar, 2011. p. 42.

${ }^{46} \mathrm{Cf}$. NYE JR, Joseph. O futuro do poder. São Paulo: Benvirá, 2012.

${ }^{47}<$ http://www.nuevorden.net/portugues/valhalla88.html>

${ }^{48}$ MAYNARD, Dilton Cândido Santos. Intolerância em Rede: Apropriações da Internet pela Extrema-Direita (1999-2009). In: Anais Eletrônicos do Il Seminário de Pós-Graduação em Ensino

de História. Faculdade São Luís de França, Aracaju/SE: 2009; Nueva Orden. Site: <http://www.nuevorden.net/main.html>. Acesso em: 8 out. 2008.
} 
histórico" e farto material doutrinário. Os idealizadores do Valhalla 88 viviam em Santa Catarina, Sul do Brasil. O sítio alcançou a significativa marca de 200 mil visitas diárias, tornando-se, assim, um dos mais atrativos links nacional-socialistas da América do Sul.

Inicialmente hospedado no provedor Libreopinion.com, o Valhalla88.com foi rastreado pela Polícia Federal e membros da Comunidade Judaica no Brasil, forçando-se a buscar "hosting" nos Estados Unidos, mas logo depois foi retirado do ar. Os neonazis brasileiros, principalmente skinheads, costumavam, pelo Valhalla88, pregar a dominação do "sangue ariano" como um elemento de identidade racial ${ }^{49}$.

O próprio nome de batismo do sítio evidencia o apelo místico que ele pretendia ter. O nome "Valhalla" tem origem na mitologia nórdica, referência ao castelo para onde seguem os guerreiros mortos em combate. O número 88 corresponde à oitava letra do alfabeto em sequência (HH), acrônimo para "Heil Hitler"50. O grupo acaba assim aproximando-se de outros neonazis conhecidos, como Alejandro Biondini/Kalki ou Miguel Serrano, o líder chileno de um fascismo mais voltado a um ethos místico. O neonazismo circulante pelos sítios nacionais, emulando exemplos da Europa e de países próximos, como a Argentina, reúne mitos, narrativas e rituais supostamente "pagãos", promovendo a superioridade da raça ariana. Segunda Adriana Dias, “estes racistas, nazistas e revisionistas constroem e atualizam mitos, inscrevendo na palavra raça uma relação simbólica, polissêmica, complexificada, enraizada numa ideologia saturada de anacronismo, contradições, ódio e insegurança, ideologia esta que os pretende heróis"51. $\mathrm{O}$ argumento do perigo iminente à raça era recorrentemente utilizado pelo Valhalla 88 . As agressões, o preconceito, a xenofobia ali reinante em nada se comparavam ao tratamento injusto e à perseguição que eles diziam sofrer do Z.O.G (Zionist Occupation Government, ou Governo Sionista de Ocupação).

\footnotetext{
49،Considerando apenas o Valhalla88, por exemplo, suas mais de mil e quinhentas páginas equivaleriam a dezessete sites médios, se levarmos em conta todos os sites e cerca de cinquenta sites se desconsideramos os grandes portais. A rede racista é, portanto, muito expressiva em tamanho: os sites se reproduzem aos milhares e a grande maioria ocupa espaço de dezenas deles". CF. DIAS, Adriana Abreu Magalhães. Os Anacronautas do Teutonismo Virtual: uma etnografia do neonazismo na Internet. Campinas, SP: [s. n.], 2007. p. 94-95.

50 SALAS, Antonio. Diário de Um Skinhead: um infiltrado no movimento neonazista. Tradução de Magda Lopes. São Paulo: Planeta, 2006.

${ }^{51}$ DIAS, Adriana Abreu Magalhães. Os Anacronautas do Teutonismo Virtual: uma etnografia do neonazismo na Internet. Campinas, SP: [s. n.], 2007. p. 26.
} 
Durante o seu período de funcionamento, o Valhalla 88 manteve um frequentado fórum, chamado Livro de Odin, espaço no qual as ideias de diferentes tendências skinheads se manifestavam. Após a expulsão do Libre Opinión, o Valhalla enfrentou dificuldades para continuar mantendo suas atividades. A revolta com a suspensão do suporte oferecido pelo site argentino aparece em diferentes comunicados. É assim no aviso dos "Nazistas Sulinos", que recebeu apoio do V88 para manter algumas informações no $\mathrm{ar}^{52}$.

Todo o caso que resultou na desativação das páginas foi tratado pelos responsáveis por tais ambientes eletrônicos como "perseguição à causa”. No caso do Valhalla 88 e do NSS, os "vermes judaicos" aparecem como os principais responsáveis por toda sorte de problema que surgisse do seu ativismo intolerante. Esta era a ótica através da qual os fascistas brasileiros, assim como os seus parceiros argentinos, interpretavam os desdobramentos de suas atividades no ciberespaço. A mesma lente foi utilizada para pensar a relação entre os estados da Federação, lente que forja a ideia fixa de exploração dos trabalhadores - brancos arianos, de franca ascendência europeia - pelos parasitas sociais, isto é, imigrantes, negros, judeus, homossexuais, comunistas e estrangeiros de um modo geral. Mas, diferentemente dos argentinos, os ativistas brasileiros se mostraram mais dispersos, sem as pretensões de formar grupos legalizados e amplos. A ideologia de "lobos solitários" parece ter tido aqui uma acolhida mais intensa.

\section{Brasil e Argentina: extremas-direitas e ciberespaço em perspectiva comparada}

No Brasil, a adoção da estrutura celular e a recorrência à ideia de "lobo solitário" aparecem com maior nitidez do que na Argentina. É assim que o "Partido NacionalSocialista Brasileiro", cujo domínio é www.nacional-socialismo.com, criado em 19 de dezembro de 2008, pouco depois do fechamento do Valhalla 88, se posiciona:

O Partido Nacional-Socialista Brasileiro não requisita filiação formal. Não existe "carteirinha" de associado. Não solicitamos qualquer informação pessoal dos nossos colaboradores; na verdade, sugerimos que tomem o máximo de precaução com todo tipo de dado que possa comprometer a

\footnotetext{
52 http://www.valhalla88.com/nazistassulinos/mensageiro88.html Acesso via www.waybackmachine.org em: 20 dez. 2012.
} 
segurança individual e do grupo ao seu redor. Saiba atuar como um "Lobo Solitário". A filiação ao partido se dá com o compromisso de cada um em promover a Cosmovisão Nacional-Socialista, a determinação individual em lutar pelo seu modo de vida. Esta é a verdadeira filiação: o compromisso com o ideal e a abnegação em prol do interesse coletivo ${ }^{53}$.

Diferente da imensa comunidade judaica existente na Argentina - a quinta maior do mundo -, com números que superam os 300 mil habitantes (numa população geral de 40.764.561), o Brasil, cuja população já ultrapassa 193 milhões, possui pouco mais de 100 mil judeus. Apesar da semelhança nos quantitativos, são outros, não os judeus, os principais alvos da extrema-direita brasileira. Funcionando como peça essencial à paranoia fascista, o elemento ameaçador, o "outro conveniente", é deslocado da figura do judeu para o nordestino, o negro ou o homossexual. Por sua vez, no caso argentino, este deslocamento, sempre ocasional, parece se expressar contra imigrantes paraguaios, peruanos e bolivianos. São eles os concebidos como pobres "rotos", doentes, sanguessugas dos recursos nacionais.

$\mathrm{Na}$ Argentina, as complexas relações entre os extremistas de direita e setores dos diferentes governos e de corporações militares tornam a compreensão do problema ainda mais difícil. A conhecida acolhida de Juan Domingo Perón a fugitivos alemães ${ }^{54}$ que participaram em diferentes posições no III Reich, bem como sua incorporação aos quadros do governo argentino, sua permanência mesmo após a queda de Perón e sua subsequente colaboração com a ditadura militar argentina evidenciam que as práticas fascistas tiveram continuadores e que as pretensões de Biondini encontram caixas de ressonâncias.

No Brasil, se os casos de antissemitismo aparecem com menor incidência, a rede tem servido para a difusão de ódio a gays, afrodescendentes e nordestinos de modo regular. Contudo, os grupos da extrema-direita aqui mencionados não devem ser vistos como um bloco homogêneo. As ideias dos integralistas logo se chocam com as dos neonazistas: "No momento em que você abraça o Brasil ou ideologias como o

\footnotetext{
53 http://www.pbagora.com.br/conteudo.php?id=20110519160010

54 Sobre isto ver: GOÑI, Uki. The Real Odessa: how Péron brought the nazi war criminals to Argentina. London: Granta Books, 2002.
} 
integralismo, estará abraçando a miscigenação, devemos nos preocupar com nossa raça, independentemente de fronteiras ou países" 55 . E os disparos atingiam aliados ilusórios e inimigos consensuais.

A longevidade de sites como o www.valhalla88.com muito indicia sobre as dificuldades de se combater a intolerância on line. Por sua vez, as constantes caçadas a gays e nordestinos nas ruas de São Paulo e em outras cidades do País sinalizam para a necessidade de se pensar com mais profundidade o problema. Outro aspecto a ser considerado é o peso das tensões regionais nas interpretações dos fascistas nacionais. Afinal de contas, a maioria dos sítios estudados foi de grupos localizados no Sul e Sudeste brasileiros ou na capital federal argentina. A plasticidade das interpretações se mostra necessária para que skinheads de Porto Alegre esqueçam que são "sudacas" frente a seus parceiros europeus ou que os carecas paulistas e alagoanos relativizem a cor da pele frente aos argumentos de supremacia. A única regularidade entre estes grupos parecem ser a homofobia e o machismo.

\section{Considerações finais}

Enquanto na Argentina percebemos uma maior organização, com tentativas de arquitetura de uma rede de trabalho e hierarquias pré-definidas, no Brasil isto não aparece de modo tão consistente, sendo os casos de ativistas "lobos solitários" os mais frequentes. No entanto, percebemos em ambas as situações a presença de atividades extremistas desde os primeiros anos da abertura da internet, em meados dos anos 1990. O processo de colonização do ciberespaço por grupos brasileiros e argentinos foi possível apenas quando a rede se tornou acessível a usuários não-especialistas

Ao final da última década do século XX, tempo que se esperava ser o começo de um longo período de paz e harmonia entre os povos, os historiadores cerravam os olhos e a intolerância ganhava espaço através de jogos eletrônicos, músicas, fotografias, planos de ataque, revisionismo histórico, ataques a judeus, imigrantes, negros, homossexuais e todos os demais "inimigos naturais" do homem branco

\footnotetext{
${ }^{55}$ http://www.valhalla88.com/valhalla.html Acesso em: 8 ago. 2006.
} 
ariano. Tudo isto era articulado graças ao uso da internet.

As páginas do ódio e seus idealizadores no Brasil e na Argentina atraíram jovens, agrediram os opositores e escaparam durantes anos de quaisquer punições. A ocupação do ciberespaço por grupos de extrema-direita progrediu a passos largos graças à desatenção e ao próprio ineditismo das redes telemáticas. Políticos, juristas, intelectuais e diferentes ativistas foram pegos de surpresa.

Outra coisa a se observar é que, ao considerarmos o universo digital dos dois países, precisamos levar em conta seus respectivos itinerários no desenvolvimento econômico e nas incorporações de transformações tecnológicas. Na Argentina, a combinação das reformas promovidas ainda no primeiro governo Ménem, que transformaram o panorama da economia nacional e baratearam as comunicações - mas ao mesmo tempo aprofundaram as diferenças sociais, promoveram deslizamentos no poder aquisitivo e na qualidade de vida de parte significativa da população -, aliadas à persistência de segmentos da ultradireita identificados com os ideais fascistas, propiciou o avanço do Partido Nuevo Triunfo na web. Porém, a fraca penetração social deste grupo foi evidenciada pelas derrotas sofridas na Justiça e pela pouca ressonância das marchas e eventos por eles convocados.

Contudo, o quadro é ainda mais complexo. Se, por um lado, podemos perceber o fracasso eleitoral de extremistas como Alejandro Biondini, as relações que ele e seus seguidores mantiveram com setores mais discretos da extrema-direita argentina evidenciam ressonâncias no discurso fascista e utilidades para eles que necessariamente não passam por sua apresentação explícita em eleições.

O PNT não conseguiu alistar milhares de seguidores como pretendia. Os poucos envolvidos, porém, cumprem papel semelhante ao da juventude hitlerista na Alemanha do III Reich. Eles são os cachorros loucos, os aterrorizadores, os detratores da oposição nas madrugadas e, frequentemente, os responsáveis pela guarda pessoal dos fascistas engravatados.

Ao migrar a maior parte das suas operações para a rede em 1999, Biondini acabou contribuindo para o intercâmbio entre diferentes e pequenos grupos de toda a América 
No Brasil, o outro conveniente parece mais difícil de ser identificado. O nosso “judeu” não é um, mas vários. Ele é o negro, o gay, o homossexual, o nordestino, o comunista, a mulher, e também o judeu. Assim, o elemento conservador é antes um aspecto comportamental do que propriamente um traço fixo de uma ideologia política. Um skinhead pode aceitar o afrodescendente, como fazem os Carecas do Brasil, os Carecas de Alagoas, mas rejeitar, perseguir e matar gays.

Ao mesmo tempo, o discurso maleável apresentado nas páginas brasileiras ocorreu principalmente quando a discussão orbitou em torno do tema do racismo, enquanto que questões ligadas ao respeito aos direitos humanos foram acompanhadas de uma marcante intolerância. Era preciso justificar a existência de "mestiços" nos grupos, mas não foram identificadas brechas a gays e todos os grupos se mostraram amplamente machistas.

Um dos corolários das contínuas adaptações dentro da ideologia fascista adotada entre os grupos brasileiros resultou na dificuldade em articular ações conjuntas e na impossibilidade da emergência de uma liderança única. Se a opção pelos lobos solitários sugere, por um lado, a fraqueza dos fascistas em ascender por vias legais, revela, por outro, a preocupante dispersão de militantes que alimentam em silêncio desejos de "vingança" contra a sociedade.

Ao realizar uma análise comparativa entre Brasil e Argentina, identificamos semelhanças preocupantes, mas também diferenças que sinalizam para as especificidades históricas de cada país. A generalização não é possível, nem interessante. Nos dois casos, percebemos a complexidade dos fascismos ressurgentes e sua maior dispersão via redes eletrônicas. Como pediu Bloch, precisamos nos adaptar ao novo e, assim, talvez, enxerguemos melhor o tempo presente. Deste modo, a análise do comportamento fascista no século XXI acentua a necessidade de se consolidar o campo 
da História Digital, pois é nele que melhor se conseguem observar ambientes como o ciberespaço, respeitando as suas especificidades.

\section{Referências Bibliográficas}

ARQUILLA, John and David Ronfeldt. Conceptual Outlines. The Advent of netwar. Santa Monica, CA: RAND Corporation, 1996. p.277. Disponível em:

<http://www.rand.org/pubs/monograph_reports/MR789>. Also available in print form. Acesso em 05/08/2011.

BACK, L, KEITH, M, SOLOMOS, John. Racism on the Internet: mapping neofascist subcultures in cyberspace. BJØRGO, T., KAPLAN, J. (Orgs.). Nation and race: the developing Euro-American racista subculture. Austin, TX: Northeastern University Press, 1998. p.73-101.

BARBOSA, Jefferson R. Ideologia e intolerância: a Extrema Direita latino-americana e a atuação no Brasil dos herdeiros do Eixo. Aurora, ano II, n. 2 p.2-11, jun., 2008.

BARTOLETTI, Susan C. Juventude hitlerista: a história dos meninos e meninas nazistas e a dos que resistiram. Trad. B.Horta. Rio de Janeiro: Relume Dumará, 2006.

BAUMAN, Zygmunt. Globalização: as consequências humanas. Trad. Marcus Penchel. Rio de Janeiro: Jorge Zahar Editor, 1999.

BAUMAN, Zygmunt. O amor líquido: sobre a fragilidade dos laços humanos. Trad. Carlos Alberto Medeiros. Rio de Janeiro: Jorge Zahar Editor, 2004.

BÉDARIDA, François. Tempo presente e presença da história. Usos \& abusos da história oralAMADO, Janaína, FERREIRA, Marieta de Moraes Ferreira. 7 ed. Rio de Janeiro: Editora FGV, 2005.p.219-232

BLOCH, Marc. A estranha derrota. Rio de Janeiro: Zahar, 2011.

BLOCH, Marc. Apologia da história ou o ofício do historiador. Rio de Janeiro: Jorge Zahar Editor, 2001.

BLOCH, Marc. Por une Histoire Comparée des societies européennes. Revue de Synthèse Historique, n. 46, p. 15-50. 
BOBBIO, Noberto. Dicionário de política. Trad. João Ferreira, Carmem varriale et al. Brasília: Editora Universidade de Brasília, 1986.

BORIN, Marta Rosa. Revionismo/Negacionismo. In: MEDERIOS, Sabrina Evangelista, SILVA, Francisco Carlos Teixeira da, VIANA, Alexander Martins. Dicionário crítico do pensamento da direita: idéias, instituições e personagens. Rio de Janeiro: FAPERJ/Mauad, 2000.p.397

BRESCIANO, Juan Andrés. I historiador y las fuentes eletrônicas: nuevos horizontes para La crítica heurística en siglo XXI. Data., Disponivel em <http;//WWW.h-debate.com/Sesión 15/05/08 Seminario "on line"> . Acesso em 12 dez. 2008.

CAMUS, Jean-Yves. Skinheads. In: MEDERIOS, Sabrina Evangelista, SILVA, Francisco Carlos Teixeira da, VIANA, Alexander Martins. Dicionário crítico do pensamento da direita: idéias, instituições e personagens. Rio de Janeiro: FAPERJ/Mauad, 2000. p.417-419

CASTELLS, Manuel. A Galáxia internet: reflexões sobre a Internet, os negócios e a sociedade. Trad. Maria Luiza X. Borges. Rio de Janeiro: Jorge Zahar Ed., 2003.

CERTEAU, Michel de. A invenção do cotidiano: artes do fazer. Trad. Ephraim Ferreira Alves. Petrópolis, RJ: Vozes, 1994.

CHAUVEAU, Agnès, Tétart, Philippe. Questões para a história do presente. Bauru, SP: EDUSC, 1999.

COHEN, Daniel J., ROSENZWEIG, Roy. Digital history: a guide to gathering, preserving, and presenting the past on the web. Philadelphia: University of Pennsylvania Press, 2006.

COSTA, Márcia Dias. Carecas do subúrbio: caminhos de um Nomadismo Moderno. Petrópolis: Vozes, 1993

DETIENNE, Marcel. Comparar o incomparável. Aparecida, São Paulo, Idéias \&

DIAS, Márcia. Carecas do subúrbio: caminhos de um Nomadismo Moderno. Petrópolis: Vozes, 1993.

EUMC - Relatório Anual 2004/2005 - observatório europeu do racismo e da xenofobia. (Parte 1). Local: EUMC, data. 
FEBRVE, Lucien. Face ao Vento. Manifesto dos Anais Novos (1946). In:

História. São Paulo: Ática, 1992. p.173-182

FEBVRE, Lucien. História. MOTA,Carlos G.(Org.). 2 ed. SP:Ática, 1992.

GABLE, Gerry, JACKSON, Paul (Orgs). Far-Right.com: nationalist extremism on the Internet. Northamton: University of Northhampton, 2012.

GEERTZ, Clifford. Uma descrição densa: por uma teoria interpretativa da cultura. In: . A interpretação das culturas. Rio de Janeiro: LTC, 1989.p.3-24.

GINZBURG, C. O nome e o como: troca desigual e mercado historiográfico. A microhistória e outros ensaios. Trad. António Narino. Lisboa: Difel/ Rio de janeiro: Bertrand Brasil, 1989. p.169-178.

GINZBURG, C. Sinais: raízes de um paradigma indiciário. Mitos, emblemas e sinais: morfologia e história. Trad. F. Carotti. São Paulo: Cia das Letras, 2002. p.143-180.

HOBSBAWM, Eric J. Era dos extremos: o breve século XX. 2 ed. São Paulo: Companhia das Letras, 1997.

HOBSBAWM, Eric J. Nações e nacionalismo desde 1870: programa, mito e realidade. Trad. Maria C. Paoli e Anna M. Quirino. Rio de Janeiro: Paz e Terra, 1990.

KERSHAW, Ian. Hitler, the germans, and the final Solution. London/Yale University Press, 2008

KOCKA, Jürgen. Comparison and beyond. History and theory, Vol. 42, No. 1 (Feb., 2003), pp. 39-44

KOLLMANN, Raúl. Sombras de Hitler: la vida secreta de las bandas neonazis argentinas. Buenos Aires: Editorial Sudamericana: 2001

KOSELLECK, Reinhart. Futuro passado: contribuição à semântica dos tempos históricos. Trad. Wilma Patrícia Maas, Carlos Almeida Pereira. Rio de Janeiro: Contraponto/Ed. PUCRio, 2006.

LE GOFF, Jacques. História e memória. Campinas, SP: Editora da UNICAMP, 1990.p.13-148. (Coleção Repertórios).

LÉVY, Pierre. Cibercultura. 2 ed. Rio de Janeiro: Editora 34, 2000. 
Luis Alberto. Breve história contemporánea de la Argentina (1916-2010). 3. ed. Buenos Aires: Fondo de Cultura Económica, 2012.

MAYNARD, Dilton (Org.) História, neofascismos e intolerância: reflexões sobre o tempo presente. São Cristóvão/rio de Janeiro: Edufs/Luminárias, 2012.

MAYNARD, Dilton C.S. A intolerância on line: aspectos da propaganda da extrema-direita brasileira na Internet. In: SIMPÓSIO NACIONAL DE HISTÓRIA, XXII, Florianópolis, 2005. Anais eletrônico... Florianópolis: Editor, 2005. Um CD-ROM.

MAYNARD, Dilton C.S. Intolerância em rede: apropriações da internet pela extremadireita (1999-2009). Revista Eletrônica Boletim do Tempo, Ano 5, n.10, p.00-00, 2010.

MAYNARD, Dilton. Escritos sobre história e internet. Rio de Janeiro: FAPITEC/Luminárias, 2011.

MEDERIOS, S. E., VALENTE, L. O Manifesto de Anders Breivik. Um atentado anunciado: Noruega, 22 de julho de 2011. Revista Estudos Políticos. n. 3, p.00-00, jul./dez. 2011

MILMAN, Luis, VIZENTINI, Paulo Fagundes. Neonazismo, negacionismo e extremismo político. Porto Alegre: Ed.UFRGS, 2000.

MOYANO, A. L. Neonazis: la seducción de la svástica. Nowtilus: Madrid, 2004..

NEUMANN, Franz. Behemoth: the structure and practice of national socialism, 1933-1944. Chicago: Ivan R. Dee/United States Memorial Museum, 2009

NORA, Pierre. Entre memória e história: a problemática dos lugares. Trad. Yara Aun Khoury. Projeto História. São Paulo, 1981.p.7-28.p.12-13

NORA, Pierre. O retorno do fato. LE GOFF, J. NORA, P. História: novos problemas. Rio de janeiro: Livraria Francisco Alves, 1976.p.179-193.

NYE JR, Joseph. O futuro do poder. São Paulo: Benvirá, 2012.

PAXTON, Robert. A anatomia do fascismo. Trad. Patrícia Zimbres e Paula Zimbres. Rio de Janeiro: Paz \& Terra, 2007.

PRADO, Maria Ligia Coelho. Repensando a história comparada da América Latina. Revista de História. Universidade de São Paulo, n. 153, p.11-33, 2005, 
PROST, Antoine. Doze lições sobre história. Tradução Guilherme João de Freitas Texeira. Belo Horizonte: Autêntica Editora, 2009.

PURDY, Sean. A História Comparada e o Desafio de Transnacionalidade. Revista de História Comparada. p.1. V.6 - N. 1 - Julho/2012. <www.hcomparada.historia.ufrj.br/revistahc/artigos/volume006_Numo01_artigo003.pdf> acesso em 23/12/2012.

QUITTNER, Joshua, STAMPER, Chris. Home pages for hate. Time. Jan. 22, 1996. Disponível em: www.time.com/time/.../0,9171,983994,00.html . Acesso em20/08/2011.

RIDGEWAY, James. Blood in the face: the Ku, Klux, Klan, Aryan Nations, Nazi skinheads, and the Rise of a New White Culture. 2 ed. New York: Thunder's Mother Press, 1995.

ROSENZWEIG, Roy. Scarcity or Abundance? preserving the past. In: Clio wired: the future on the past in the digital age. New York: Columbia University Press, 2011.

SALAS, Antonio. Diário de um skinhead: um infiltrado no movimento neonazista. Trad. Magda Lopes. São Paulo: Planeta, 2006.

SEIGNOBOS, Charles. História comparada dos povos da Europa. 2 ed. Rio de Janeiro: José Olympio, 1945.

SERKAN, Gül. Method and practice in comparative history. Karadeniz Araştırmaları, ano 2010, n.26, p. 143-158, 2010. Disponível em: <

http://www.karam.org.tr/Makaleler/91886581_gul.pdf> Acesso em 12/12/2012.

SILVA, Francisco Carlos T. Um estrondo na Noruega: quando o diabo bate à porta [1]. Carta Maior. 25/07/2011. Disponível em

<http://www.cartamaior.com.br/templates/colunaMostrar.cfm?coluna_id=5134>. Acesso em

SILVA, Francisco Carlos Teixeira da, VIANA, Alexander Martins. Dicionário crítico do pensamento da direita: idéias, instituições e personagens. Rio de Janeiro: FAPERJ/Mauad, 2000.

SILVA, Francisco Carlos Teixeira da. O retorno: é primavera em Zwickau, Alemanha. Carta Maior. 24/01/2012. Disponível em

$<$ http://www.cartamaior.com.br/templates/colunaMostrar.cfm?coluna_id=5423 $>$. Aacesso em: .

SILVA, Francisco Carlos Teixeira da. Neofascismo. Revista Eletrônica Boletim do Tempo Presente, v.00, n.00, data. Disponívlel em: 
http://www.tempopresente.org/index.php?option=com_content\&task=view\&id=34\&ltem id $=124$. Acesso em 29/03/2008.

SILVA, Francisco Carlos Teixeira da. O debate do Holocausto como paradigma da intolerância. Revista Eletrônica Carta Maior, v.00, n.00, p.00-00, data. Disponível em< www.cartamaior.com.br> acesso em 28/03/2008; disponível também via http://www.tempopresente.org/index.php?option=com_content\&task=view\&id=1467\&lt emid=124. Accesso em 29/03/2008.

SILVA, Francisco Carlos Teixeira da. O século XX: entre luzes e sombras. In: O século sombrio: uma história geral do século XX. Rio de Janeiro: Elsevier, 2004.p.1-25.

THEML, Neyde; BUSTAMANTE, Regina. História Comparada: Olhares Plurais. Revista de História Comparada. v.1, n.1, p.00-00, Junho 2007. 